\title{
Association of Meat Intake with Overweight and Obesity among School-aged Children and Adolescents
}

\author{
Sun Mi Shin* \\ Department of Nursing, Joongbu University, Geumsan, Korea
}

Background: This study aimed to investigate the association of overweight and obesity with red and white meat intake among children and adolescents using secondary survey data $(n=16,261)$ from in-school Student Health Examination conducted in 2006 and 2007.

Methods: Descriptive statistics was conducted to investigate the frequency of meat intake per week. The body mass index (BMI) grades for obesity in boys and girls were classified using the standards from the 2007 Korean National Growth Charts. The association of meat intake with overweight and obesity was analyzed using Chisquare test and multiple logistic regression.

Results: The proportion of subjects with no intake/week vs. daily meat intake/week was $5.9 \%$ and $5.5 \%$, respectively. No intake of meat was more frequent in those who were female and in middle school, whereas daily meat intake was more frequent in those who were male and in high school. The proportions of overweight and obesity in the no meat intake/week group and daily meat intake/week group were $12.3 \%$ and $11.1 \%$ vs. $8.1 \%$ and $9.9 \%$, respectively. After adjusting for confounding variables, including age; consumption of instant noodles, soft drinks and fast foods, dairy products, and fruits and vegetables; and skipping breakfast, the odds ratios of overweight and obesity in the no meat intake/week group were 1.41 times higher (95\% confidence interval, 1.04-1.85) than those in the daily meat intake/week group.

Conclusion: It is important to consider correcting the perception about meat intake and obesity and avoid restricting meat intake to prevent overweight and obesity among children and adolescents.

Key words: School-aged, Children, Adolescents, Meat, Overweight, Obesity

\author{
Received August 24, 2016 \\ Reviewed September 24, 2016 \\ Accepted November 12, 2016 \\ *Corresponding author \\ Sun Mi Shin \\ (iD) \\ http://orcid.org/0000-0002-5519-2412 \\ Department of Nursing, Joongbu \\ University, 201 Daehak-ro, Chubu- \\ myeon, Geumsan-gun, Chungnam \\ 32713, Korea \\ Tel: +82-41-750-6255 \\ Fax: +82-41-750-6416 \\ E-mail: healthteam@joongbu.ac.kr
}

\section{INTRODUCTION}

Obesity in children and adolescents is strongly associated with the incidence of cardiovascular diseases, diabetes, and cancer in the adulthood and results in a correspondingly high risk of mortality; therefore, a high rate of obesity in adolescents is one of the global health issues of this era. ${ }^{1}$ Diet in children and the adolescent population has direct effects on both physical growth and mental maturation. Moreover, eating habits established during the adolescent stage are usually persistent throughout adult and late stages of life, and therefore, it has a decisive long-term effect on the health condi- tion of an individual. ${ }^{1,2}$ Selection of appropriate diet for children and adolescents to prevent obesity and maintain normal weight is one of the key research questions. Furthermore, improper understanding of dietary habits according to age and gender makes it difficult to set goals for a change in diet-related actions or habits. ${ }^{3}$

Currently, known obesity risk factors include not only genetic factors and reduced physical activity but also excessive intake of high-caloric food, including sugars, meat with saturated fat, and complex carbohydrate-based food. Furthermore, to prevent and manage obesity, recommending the consumption of vegetables and fruits that contain abundant dietary fibers over meat has been a so- 
cial convention. Previous studies showed a quantitative proportional relationship between meat intake and increased weights since meat has high-fat content and relatively high calories compared to vegetables. ${ }^{46}$ However, results from a study showed that high protein diet has latent benefits of obesity control by providing consistent satiety and assisting in body energy production. ${ }^{7}$ Moreover, previous intervention studies in overweight and obese subjects have shown that weight loss was greater when following a high protein diet than a high carbohydrate diet. ${ }^{8-13}$ In these previous studies, the effects of meat consumption on obesity were not consistent. Furthermore, most studies that assessed the association between obesity and meat intake were international studies, and despite their high importance, domestic studies based on a large population are rarely carried out in Korea. Even fewer studies have been performed to assess the association between diet and overweight/ obesity in children and adolescents by year in school. Paradoxically, the interest in the association between dietary intake of children and adolescents and overweight/obesity remains very high.

The purpose of this study was to investigate the association between red/white meat intake and overweight/obesity in schoolaged children and adolescents to provide foundational evidence for both educations on desirable eating habits for school-aged adolescent population and policies on school lunches. The following were the specific purposes of the study: first, to identify the frequency of the intake of red and white meat (including beef, pork, chicken, etc.) in a school-aged adolescent population; second, to assess the distribution of overweight/obese subjects according to their meat intake level; and third, to identify the effects of meat intake on overweight/obesity.

\section{METHODS}

\section{Materials and subjects}

This study was a cross-sectional descriptive study to assess the association between the frequency of weekly meat intake and overweight/obesity in elementary, middle, and high school students. The subjects of the study are 16,819 school-aged students that had in-school Student Health Examinations performed by the Seoul School Health Promotion Center in 2006 and 2007 (8,188 students in 2006 and 8,631 students in 2007). Among them, 16,797
(99.9\%) responded to questions related to dietary intake and were included in the finalized study cohort.

\section{Data collection and ethical considerations}

Secondary data from the Student Health Examination and survey performed by the Seoul School Health Promotion Center in 2006 and 2007 to assess the health conditions of the school-aged population were used in this study. Height and weight were measured by a standard method, using an identical tool and trained examiner. The survey was performed to assess dietary pattern, physical activities, and mental state. Younger elementary school children were asked to complete the survey under parental guidance.

For ethical considerations, all subjects were notified of the purpose of the study. The subjects were asked to indicate with a check mark on a form of their agreement to participate in the study, and written informed consent was obtained. Furthermore, data for personal identification (i.e., birth date, school name, and name) were completely removed from all data analyses, and all statistical analyses involved group level data rather than individual data. The author requested by the Seoul School Health Promotion Center, the data analysis center of this dataset, to analyze the data obtained consent of the Center for possible future academic publications on the contents required in the development of school health policies.

\section{Measurement variables}

Variables used in this study from the original dataset were categories and indices that were assessed in the elementary, middle, and high school students, including demographic variables (gender, assessment year, and school year) and dietary intake variables (intake frequency of meat, instant noodles, soft drinks, fast food, milk and dairy products, and fruits and vegetables). In addition, breakfast habit, which is associated with overall dietary habits, was used as a confounding variable.

Obesity level were assessed by body mass index (BMI) $\left(\mathrm{kg} / \mathrm{m}^{2}\right)$, which was measured using the actual height and weight measurements among testing variables. According to the 2007 Korean National Growth charts of BMI based on age and gender of the Korean Society of Pediatrics ${ }^{14},<5 \%$ was considered underweight, $\geq 5 \%$ but $<85 \%$ were normal weight, $\geq 85 \%$ but $<95 \%$ were overweight, and finally $>95 \%$, or BMI $>25$, were considered obese. 
Among dietary intake variables, meat intake habits - the key factor in this study - were assessed by asking the question "In general, how many times do you consume meat (beef, pork, chicken, etc.) in a week?"; the subjects were asked to give a single multiple choice answer with following options: (1) None, (2) Daily, (3) 1-2 times, and (4) 3-5 times. Subjects who answered "(1) None” were considered to have no meat intake and "(2) Daily" were considered to have daily meat intake.

Aside from meat intake, other dietary intake variables were categorized into five groups: instant noodles; soft drinks (excluding fruit juice); fast food (pizza, hamburger, fried food); milk and dairy products; or fruits and vegetables. The same question of "In general, how many times do you consume these foods in a week?" was asked of the aforementioned food groups, and the subjects were once again asked to give a single multiple-choice answer with following options: (1) None, (2) Daily, (3) 1-2 times, and (4) 3-5 times. Moreover, for a confounding variable associated with a dietary intake that needs to be controlled, the survey question asked "In general, do you eat breakfast?"; the subjects were asked to give a single multiple-choice option from following options: (1) Eating daily, (2) Eating usually, (3) Skipping usually, and (4) Skipping nearly. Other obesity-associated confounding factors such as physical activities, mental health, and hobbies were excluded from the analysis as the survey questions were not identical among elementary, middle and high schools or not included in the surveys for certain schools.

\section{Analysis methods}

Descriptive statistics and the Chi-square test were used to assess the percentage of subjects with no meat intake and daily meat intake, distribution of underweight, overweight, and obesity by the frequency of meat intake, and percentage of subjects with no meat intake and daily meat intake according to obesity levels. Furthermore, to understand the effects of the frequency of meat intake on overweight and obesity and to examine the odds ratios (ORs) of overweight and obesity, multiple logistic regression was performed with the general characteristics, dietary intake variables, and breakfast habits as confounding variables.

In all analyses, the missing values for each variable were excluded from the results, and the results were considered statistically significant at a $P<0.05$. All statistical analyses were performed using SAS software (version 9.4; SAS Institute Inc., Cary, NC, USA).

\section{RESULTS}

Among 16,261 subjects in the study, 8,408 (51.7\%) were male and $7,853(48.3 \%)$ were female. Of the entire cohort, $5.9 \%$ had no weekly meat intake and $5.5 \%$ had a daily meat intake. When divided by gender, male and female subjects showed distributions of $5.5 \%$ and $6.3 \%$ for no meat intake and $6.3 \%$ and $4.7 \%$ for daily meat intake, respectively, indicating a higher frequency of daily intake in males than in females $(P<0.001)$. Moreover, the meat intake frequencies of male and female subjects for each year were compared. In 2006, the percentages of male and female subjects with no meat intake were $5.6 \%$ and $6.1 \%$ and with daily meat intake were $6.5 \%$ and $4.4 \%$, respectively, showing a significant difference between the gender $(P<0.001)$. Similarly, in 2007, the percentages of male and female subjects with no meat intake were $5.5 \%$ and $6.4 \%$ and with daily meat intake were $6.0 \%$ and $5.0 \%$, respectively, indicating a higher frequency of no intake in females and daily intake in males for both years $(P=0.016)$ (Table 1).

The cohort was composed of 8,122 (50.0\%) elementary school students, 4,009 (24.6\%) middle school students, and 4,130 (25.4\%) high school students. The frequency of no meat intake among subjects was higher in the middle school (7.1\%) than in the lower year $(5.9 \%)$ or upper year $(5.5 \%)$ elementary school and high school (5.0\%) cohort. The frequency of daily meat intake among subjects was highest in the high school (8.3\%) than in the lower year $(3.2 \%)$ or upper year $(4.0 \%)$ elementary school and middle school $(6.6 \%)$ cohort $(P<0.001)$. Furthermore, among lower year elementary school students (grades 1st, 2nd, and 3rd), the percentages of male and female subjects with no meat intake were $5.8 \%$ and $6.1 \%$ and with daily meat intake were $3.7 \%$ and $2.6 \%$, respectively $(P=0.03)$; whereas, among the upper year elementary school students (grades 4th, 5th, and 6th), the percentages of male and female subjects with no meat intake were $5.3 \%$ and $5.8 \%$ and with daily meat intake were $4.6 \%$ and $3.3 \%$, respectively $(P=0.05)$, showing differences between gender. For middle school students, the percentages of male and female subjects with no meat intake were $6.7 \%$ and $7.5 \%$ and with daily meat intake were $8.0 \%$ and $5.1 \%$, respectively, demonstrating significant differences be- 
Table 1. Frequency of meat intake per week by general characteristics

\begin{tabular}{|c|c|c|c|c|c|c|c|c|}
\hline \multicolumn{2}{|l|}{ Classification } & Subjects & No intake & 1-2 times & 3-5 times & Daily times & $\chi^{2}$ & $P$ \\
\hline \multicolumn{2}{|l|}{ Total } & $16,261(100)$ & $958(5.9)$ & $9,967(61.3)$ & $4,437(27.3)$ & $899(5.5)$ & & \\
\hline \multicolumn{2}{|l|}{ Male } & $8,408(51.7)$ & $465(5.5)$ & $5,044(60.0)$ & $2,371(28.2)$ & $528(6.3)$ & 31.7 & $<0.001$ \\
\hline \multicolumn{2}{|l|}{ Female } & $7,853(48.3)$ & $493(6.3)$ & $4,923(62.7)$ & 2,066 (26.3) & $371(4.7)$ & & \\
\hline \multicolumn{2}{|l|}{ Year 2006} & $7,796(47.9)$ & $456(5.9)$ & 4,881 (62.6) & $2,029(26.0)$ & $430(5.5)$ & 12.9 & 0.005 \\
\hline \multicolumn{2}{|l|}{ Year 2007} & $8,465(52.1)$ & $502(5.9)$ & $5,086(60.1)$ & $2,408(28.5)$ & $469(5.5)$ & & \\
\hline \multicolumn{2}{|l|}{ Elementary school_lower } & $4,057(25.0)$ & $241(5.9)$ & $2,717(67.0)$ & $969(23.9)$ & $130(3.2)$ & 396.3 & $<0.001$ \\
\hline \multicolumn{2}{|l|}{ Elementary school_upper } & $4,065(25.0)$ & $225(5.5)$ & $2,778(68.3)$ & $900(22.1)$ & $162(4.0)$ & & \\
\hline \multicolumn{2}{|l|}{ Middle school } & $4,009(24.6)$ & $284(7.1)$ & 2,321 (57.9) & $1,138(28.4)$ & $266(6.6)$ & & \\
\hline \multicolumn{2}{|l|}{ High school } & $4,130(25.4)$ & $208(5.0)$ & $2,151(52.1)$ & $1,430(34.6)$ & 341 (8.3) & & \\
\hline \multirow[t]{2}{*}{ Year 2006} & $M$ & $4,122(52.9)$ & $231(5.6)$ & $2,505(60.8)$ & $1,117(27.1)$ & $269(6.5)$ & 25.7 & $<0.001$ \\
\hline & $\mathrm{F}$ & $3,674(47.1)$ & $225(6.1)$ & $2,376(64.7)$ & $912(24.8)$ & $161(4.4)$ & & \\
\hline \multirow[t]{2}{*}{ Year 2007} & $M$ & $4,286(50.6)$ & $234(5.5)$ & $2,539(59.2)$ & $1,254(29.3)$ & $259(6.0)$ & 10.2 & 0.016 \\
\hline & $\mathrm{F}$ & $4,179(49.4)$ & $268(6.4)$ & $2,547(61.0)$ & $1,154(27.6)$ & $210(5.0)$ & & \\
\hline \multirow[t]{2}{*}{ Elementary school_lower } & $M$ & $2,137(52.7)$ & $124(5.8)$ & $1,398(65.4)$ & $535(25.0)$ & $80(3.7)$ & 8.4 & 0.030 \\
\hline & $\mathrm{F}$ & $1,920(47.3)$ & $117(6.1)$ & $1,319(68.7)$ & $434(22.6)$ & $50(2.6)$ & & \\
\hline \multirow[t]{2}{*}{ Elementary school_upper } & $M$ & 2,164 (53.2) & $115(5.3)$ & $1,450(67.0)$ & $500(23.1)$ & $99(4.6)$ & 7.6 & 0.050 \\
\hline & $\mathrm{F}$ & 1,901 (46.8) & $110(5.8)$ & $1,328(69.9)$ & $400(21.0)$ & $63(3.3)$ & & \\
\hline \multirow[t]{2}{*}{ Middle school } & $M$ & $2,101(52.4)$ & $141(6.7)$ & $1,179(56.1)$ & $612(29.1)$ & $169(8.0)$ & 17.3 & $<0.001$ \\
\hline & $F$ & $1,908(47.6)$ & $143(7.5)$ & $1,142(59.9)$ & $526(27.6)$ & $97(5.1)$ & & \\
\hline \multirow[t]{2}{*}{ High school } & $M$ & $2,006(48.6)$ & $85(4.2)$ & $1,017(50.7)$ & $724(36.1)$ & $180(9.0)$ & 11.2 & 0.01 \\
\hline & $F$ & $2,124(51.4)$ & $123(5.8)$ & 1,134 (53.4) & 706 (33.2) & $161(7.6)$ & & \\
\hline
\end{tabular}

Data shown are number (percent) by Chi-square.

Elementary school_lower means lower year elementary school students (grades 1st, 2nd, and 3rd).

Elementary school_upper means upper year elementary school students (grades 4th, 5th, and 6th).

$M$, male; F, female.

Table 2. Proportion of underweight, normal, overweight, and obesity by frequency of meat intake

\begin{tabular}{lcccccc}
\hline Classification & Subjects & No intake & $1-2$ intakes & $3-5$ intakes & Daily intakes & $\chi^{2}$ \\
\hline Total & $16,261(100)$ & $958(100)$ & $9,967(100)$ & $4,437(100)$ & $899(100)$ & \\
Underweight & $664(4.1)$ & $35(3.7)$ & $399(4.0)$ & $185(4.2)$ & $45(5.0)$ & 32.4 \\
Normal & $12,372(76.1)$ & $699(73.0)$ & $7,518(75.4)$ & $3,463(78.1)$ & $692(77.0)$ & $<0.001$ \\
Overweight & $1,543(9.5)$ & $118(12.3)$ & $998(10.0)$ & $354(8.0)$ & $73(8.1)$ & \\
Obesity & $1,682(10.3)$ & $106(11.1)$ & $1,052(10.6)$ & $435(9.8)$ & $89(9.9)$ & \\
< Overweight & $13,036(80.2)$ & $734(76.6)$ & $7,917(79.4)$ & $3,648(82.2)$ & $737(82.0)$ & 24.6 \\
$\geq$ Overweight & $3,225(19.8)$ & $224(23.4)$ & $2,050(20.6)$ & $789(17.8)$ & $162(18.0)$ & $<0.001$ \\
\hline
\end{tabular}

Data shown are number (percent) by Chi-square.

tween gender $(P<0.001)$. Lastly, for high school students, the percentages of male and female subjects with no meat intake were $4.2 \%$ and $5.8 \%$ and with daily meat intake were $9.0 \%$ and $7.6 \%$, respectively; yet again, the results demonstrated gender-based significant differences $(P=0.01)$ (Table 1$)$.

In subjects with no meat intake vs. with daily meat intake, the frequencies of underweight, overweight, and obesity were $3.7 \%$ vs. $5.0 \%, 12.3 \%$ vs. $8.1 \%$, and $11.1 \%$ vs. $9.9 \%$, respectively, indicating a higher frequency of underweight and lower frequencies of over- weight and obesity in the subjects with daily meat intake $(P<$ 0.001). Furthermore, when the subjects were categorized into two groups based on weight (less than overweight or overweight/obesity), the frequencies were $76.6 \%$ and $23.4 \%$ in the subjects with no meat intake while the frequencies were $82.0 \%$ and $18.0 \%$ in the subjects with daily meat intake, showing a lower frequency of overweight subjects in the daily meat intake group $(P<0.001)$ (Table 2$)$. Among 1,857 subjects with either no meat intake or daily meat intake, 386 were overweight or obese (58.0\% had no meat intake, 
Table 3. The proportion of meat intake by obesity index

\begin{tabular}{|c|c|c|c|c|c|}
\hline Obesity index & Subjects & No intake & Daily intakes & $\chi^{2}$ & $P$ \\
\hline Total & $1,857(100)$ & 958 (51.6) & 899 (48.4) & & \\
\hline Underweight & $80(100)$ & $35(43.8)$ & $45(56.3)$ & 11.5 & 0.009 \\
\hline Normal & $1,391(100)$ & 699 (50.3) & 692 (49.8) & & \\
\hline Overweight & 191 (100) & $118(61.8)$ & 73 (38.2) & & \\
\hline Obesity & $195(100)$ & 106 (54.4) & $89(45.6)$ & & \\
\hline$<$ Overweight & $1,471(100)$ & 734 (49.9) & 737 (50.1) & 8.1 & 0.004 \\
\hline$\geq$ Overweight & 386 (100) & 224 (58.0) & $162(42.0)$ & & \\
\hline
\end{tabular}

Data shown are number (percent) by Chi-square.

and $42.0 \%$ had daily meat intake), showing that the percentage of overweight or obese is higher among the subjects with no meat intake $(P=0.004)$ (Table 3$)$.

The effects of meat intake on overweight or obesity were assessed with OR. Variables such as gender, survey year, dietary habits, and breakfast intake were included as confounding variables. Furthermore, the author assessed two model groups by dividing the subjects differently. Group 1 divided the subjects by meat intake per week (i.e., no meat intake, 1-2 times/week, 3-5 times/ week, or daily intake). Group 2 only included those with no meat intake or daily meat intake.

The results showed that after controlling for confounding variables, the OR of overweight and obesity was higher in subjects with no meat intake in Group 1 (1.32; 95\% CI, 1.04-1.67) and subjects with no meat intake in Group 2 (1.41; 95\% CI, 1.08-1.85). Other variables with effects on overweight or obesity were as follows: males over females with OR 1.38 (95\% CI, 1.28-1.50), middle school students over lower year elementary school students with OR 0.84 (95\% CI, 0.75-0.95) in Group 1; and no milk intake over daily milk intake with OR 0.61 (95\% CI, 0.39-0.96) in Group 2 (Table 4).

\section{DISCUSSION}

Known factors associated with weight gain are Western dietary habits ${ }^{15-17}$ and a lifestyle lacking in physical activities. ${ }^{18,19}$ Furthermore, changes such as the replacement of healthy traditional Korean meals with fast food are causing weight gain..$^{20}$ As they age, children tend to have a reduced consumption of fruits, vegetables, and milk and an increased consumption of soft drinks. ${ }^{21,22}$ Most children are not following the standard guideline of desirable dietary habit. ${ }^{20,23}$
Nutritional intake, and more specifically, dietary habits, is a key factor of weight control in school-aged children and the adolescent population. However, very few studies have assessed the association between meat intake and obesity at any age group, and even fewer for children and adolescent population. An improper understanding of dietary habits according to age and gender is a limiting factor of various interventions for health promotion and obesity controlling strategies. Therefore, the association between dietary habits and obesity is an interesting topic for researchers. ${ }^{3}$ This study utilized the secondary survey data on 16,261 students, who had inschool Student Health Examinations and surveys performed by the Seoul School Health Promotion Center in 2006 and 2007, assessed the frequency of weekly meat intake, and assessed the association between meat intake and overweight/obesity.

The results showed that $5.9 \%$ of the subjects had no meat intake per week, and $5.5 \%$ had daily meat intake per week. Distribution by gender showed no meat intake in $5.5 \%$ and $6.3 \%$ of male and female subjects, respectively; whereas, daily meat intake was $6.3 \%$ and $4.7 \%$ of male and female subjects, respectively. The frequencies were higher for daily intake in males and no intake in females $(P<$ 0.001). Compared to a previous study in Spain, the frequencies of no meat intake per week for students in grades 8 th and 10th and grade 12 th were $4.1 \%$ and $2.6 \%$ in males and $4.6 \%$ and $4.2 \%$ in females, respectively; whereas the frequencies of daily meat intake per week for students in grades 8 th and 10th and grade 12 th were $4.9 \%$ and $5.7 \%$ in males and $3.9 \%$ and $5.6 \%$ in females, respectively. ${ }^{23}$ In this study, the frequencies of no meat intake were higher in male middle school students than high school students (6.7\% vs. $4.2 \%$ ) and in female middle school students than high school students (7.5\% vs. $5.8 \%$ ). Similarly, the frequencies of daily meat intake were also higher in this study than in the Spanish study in male middle 
Table 4. Odds ratios of meat intake for overweight and above by multiple logistic regression

\begin{tabular}{|c|c|c|c|c|}
\hline \multirow{2}{*}{ Classification } & & & \multicolumn{2}{|c|}{ 20verweight } \\
\hline & & & $\begin{array}{c}\text { Group } 1(n=3,225) \\
\text { OR }(95 \% \mathrm{Cl})\end{array}$ & $\begin{array}{c}\text { Group } 2 \text { (n=386 } \\
\text { OR }(95 \% \mathrm{CI})\end{array}$ \\
\hline \multirow[t]{2}{*}{ Gender } & Female & & 1.00 & 1.00 \\
\hline & Male & & $1.38(1.28-1.50)$ & $1.18(0.94-1.50)$ \\
\hline \multirow[t]{2}{*}{ Survey year } & 2006 & & 1.00 & 1.00 \\
\hline & 2007 & & $1.12(1.04-1.21)$ & $1.18(0.94-1.49)$ \\
\hline \multirow[t]{4}{*}{ School grade } & Elementary school_lower & & 1.00 & 1.00 \\
\hline & Elementary school_upper & & $1.10(0.99-1.23)$ & $1.14(0.80-1.62)$ \\
\hline & Middle school & & $0.84(0.75-0.95)$ & $1.15(0.81-1.63)$ \\
\hline & High school & & $0.95(0.84-1.08)$ & $1.17(0.82-1.69)$ \\
\hline \multirow[t]{28}{*}{ Intakes per week } & Instant noodles & No & $0.67(0.43-1.06)$ & $0.58(0.25-1.36)$ \\
\hline & & $1-2$ times & $0.69(0.44-1.08)$ & $0.59(0.25-1.37)$ \\
\hline & & 3-5 times & $0.44(0.27-0.72)$ & $0.55(0.21-1.44)$ \\
\hline & & Everyday & 1.00 & \\
\hline & Soft drink (except juice) & No & $1.29(1.03-1.60)$ & $1.61(0.95-2.72)$ \\
\hline & & $1-2$ times & $1.13(0.92-1.40)$ & $1.39(0.84-2.30)$ \\
\hline & & 3-5 times & $1.09(0.87-1.37)$ & $0.84(0.47-1.50)$ \\
\hline & & Everyday & 1.00 & 1.00 \\
\hline & Fast foods (pizza, hamburger, fry fritters) & No & $1.41(0.73-2.70)$ & $1.21(0.42-3.51)$ \\
\hline & & $1-2$ times & $1.31(0.68-2.52)$ & $1.44(0.51-4.05)$ \\
\hline & & 3-5 times & $1.37(0.69-2.74)$ & $1.60(0.54-4.86)$ \\
\hline & & Everyday & 1.00 & 1.00 \\
\hline & Milk, milk products & No & $0.83(0.69-0.99)$ & $0.61(0.39-0.96)$ \\
\hline & & 1-2 times & $0.93(0.83-1.05)$ & $0.72(0.50-1.04)$ \\
\hline & & 3-5 times & $0.86(0.77-0.96)$ & $0.89(0.62-1.26)$ \\
\hline & & Everyday & 1.00 & 1.00 \\
\hline & Fruit, vegetable (except kimchi) & No & 1.09 (0.86-1.39) & $1.05(0.63-1.76)$ \\
\hline & & 1-2 times & $1.05(0.94-1.18)$ & $1.28(0.91-1.81)$ \\
\hline & & 3-5 times & $1.05(0.96-1.15)$ & $1.10(0.80-1.51)$ \\
\hline & & Everyday & 1.00 & 1.00 \\
\hline & Meat (beef, pork, fowl et al.) & No & $1.32(1.04-1.67)$ & $1.41(1.08-1.85)$ \\
\hline & & 1-2 times & $1.13(0.94-1.34)$ & - \\
\hline & & 3-5 times & $0.98(0.81-1.19)$ & - \\
\hline & & Everyday & 1.00 & 1.00 \\
\hline & Breakfast & Eating daily & 1.00 & 1.00 \\
\hline & & Eating usually & $1.07(0.97-1.18)$ & $0.97(0.71-1.29)$ \\
\hline & & Skipping usually & $1.09(0.94-1.27)$ & $1.12(0.70-1.75)$ \\
\hline & & Skipping nearly & $1.19(1.03-1.41)$ & 1.07 (0.71-1.61) \\
\hline
\end{tabular}

Data shown are odds ratio (95\% Cl) adjusted for gender, survey year, school grade, food intakes/week and breakfast by multiple logistic regression.

Group 1 included all subjects.

Group 2 included only no meat intake and daily meat intake per week.

Elementary school_lower means lower year elementary school students (grades 1st, 2nd, and 3rd).

Elementary school_upper means upper year elementary school students (grades 4th, 5th, and 6th).

$\mathrm{OR}$, odds ratio; $\mathrm{Cl}$, confidence interval.

and high school students ( $8.0 \%$ and $9.0 \%$, respectively) and female middle and high school students (5.1\% and $7.6 \%$, respectively).

This study also assessed the meat intake according to school age (i.e., elementary, middle, and high school students). The frequency of no meat intake was highest in middle school students (7.1\%) and daily meat intake was highest in high school students (8.3\%) 
$(P<0.001)$. In a study involving Chinese adolescents, the researchers showed that the highest frequencies of meat intake occurred at the age of first sperm production for males and menarche (first menstrual period) for females. ${ }^{1}$ In other words, Chinese adolescents had the highest frequency of meat intake corresponding to the age of middle school students in Korea. On the contrary, the frequency of meat intake was the highest in high school and lowest in middle school age in this study. These results are reflecting the current situation in Korea where middle school students who have a relatively lower academic burden and increased interest in their appearance tend to limit their meat intake to lose weight to become more physically attractive, while high school students who have a heavier academic burden cannot limit their meat intake in order to maintain their health and energy to study.

In this study, the percentages of overweight (12.3\%) and obese (11.1\%) subjects were higher in those with no meat intake than with daily meat intake $(8.1 \%$ overweight and $9.9 \%$ obese $)(P<0.001)$. Moreover, when considering the 386 subjects of overweight or obese among the 1,857 subjects with either no meat intake or daily meat intake as $100 \%$, $58.0 \%$ had no meat intake while $42.0 \%$ had daily meat intake. Again, these results indicate higher percentages of obesity in the subjects with no meat intake $(P<0.01)$.

Previous studies are also in agreement with author's findings that the frequencies of overweight and obesity are higher in subjects with no meat intake $\mathrm{e}^{7,24}$, and they provided a logical explanation of this observation, suggesting that the high protein content in meat provides prolonged satiety and relatively increased calories consumption compared to a vegetarian diet, eventually leading to latent benefits of suppressing obesity. ${ }^{25}$ Moreover, several intervention studies on obesity management have shown better weight loss when following a high protein diet..$^{8-13}$

Meanwhile, some of the previous studies have shown that total meat consumption was associated with weight gain even after controlling for factors such as smoking, and gender. ${ }^{4,5,26}$ Moreover, there are suggestions that when assessing the association between weight and meat intake, meat by itself should not be considered a factor because the effects of protein on weight are coming not only from meat consumption but also from other diet sources including dairy products and vegetables. ${ }^{27-29}$ In Group 1, the OR of overweight/obesity was 1.32 (95\% CI, 1.04-1.67) for subjects with no meat intake over daily meat intake. In Group 2, the OR of overweight/obesity was 1.41 (95\% CI, 1.08-1.85) for subjects with no meat intake over daily meat intake. Therefore, even after controlling for potential confounding variables, the results showed that meat consumption resulted in lower obesity percentages, directly rebutting previous results saying that meat consumption results in weight gain and supporting other previous results showing higher frequency of overweight/obesity in the subjects with no meat intake.

Vegetables and fruits have similar nutritional characteristics, and people who consume lots of fruits tend to consume lots of vegetables as well. ${ }^{26}$ Individuals who consume a large amount of fruits and vegetables tend to have a lower consumption of meat (more specifically, processed meat associated with weight gain), saturated fat, and processed carbohydrates. ${ }^{26,29} \mathrm{~A}$ few studies have shown that although fruit and vegetable consumption did not result in a weight gain, the effects of fruit and vegetable consumption on weight loss were not uniform among different studies. It has been claimed that since vegetables can be cooked and replace meat as a meal, they should be considered different from fruits, which are normally uncooked and typically consumed as a part of dessert. ${ }^{26}$ In this study, there was no significant association between the consumption of vegetables or fruits and overweight/obesity.

A previous study that evaluated the association between milk and dairy products and obesity showed either no effect or inverse proportional relationship ${ }^{30}$ due to low body fat content. ${ }^{31,32}$ However, along with concerns of lactose intolerance, allergic response, and bovine growth hormones and antibiotic use, the debate about the effect of dairy product on weight gain according to the amount and types of dairy product consumed continues. In particular, a previous study has shown that the energy provided by milk and dairy products resulted in increased fat content and abdominal fat in male adolescents. ${ }^{3}$ Similarly, in this study, the OR of overweight/obesity was 0.83 (95\% CI, 0.69-0.99) in Group 1 and 0.61 (95\% CI, 0.390.96) in Group 2 for the subjects with no dairy product intake while using the subjects with a daily intake of dairy products as the reference group. Therefore, in future studies, the association of different types of dairy products with obesity should be investigated.

Among other potential confounding factors, the OR of overweight/obesity was 1.38 (95\% CI, 1.28-1.50) for males over females. This result agrees with a previous study showing a higher 
frequency of obesity in males. ${ }^{33}$ The OR was 0.84 (95\% CI, 0.750.95 ) for middle school students over lower year elementary school students (grades 1st, 2nd, and 3rd). Moreover, the OR was 0.44 (95\% CI, 0.27-0.72) for subjects with instant noodle intake of 3-5 times a week over daily instant noodle intake, and the OR was 1.19 (95\% CI, 1.03-1.41) for the subjects with a nearly skipping breakfast over daily breakfast consumption. Meanwhile, factors such as soft drink or fast food had no association with overweight/obesity.

The frequency of meat consumption in school-aged population was investigated and showed that even after controlling for potential confounding factors, the OR of overweight/obesity was lower for the subjects with meat intake compared to those with no meat intake. Therefore, previous studies suggesting limited meat consumption for weight control are not entirely true. The author suggests the following steps based on this study results.

First, the wrong health belief held by the public about meat and obesity - in other words, vegetables and fruits have low calories and high fibers and therefore will prevent weight gain, while meat has high saturated fat and high calories and therefore will result in weight gain $^{25}$ - should be reconsidered. Moreover, through school health promotion/education, it needs to advertise to the students and their parents that balanced consumption of meat will not cause obesity.

Second, the school lunch system of the survey years of this study was already established, and even though the lunches were designed to contain meat for a balanced diet, some subjects had no meat intake. Therefore, at each school, they should monitor whether or not meat is provided for student lunches and also whether or not the student actually consumes the meat.

More specifically, there are ongoing active discussions on providing breakfast at school and an increased incidence of school-based food programs for students due to an increased number of both parents working and consequent after-school programs. Therefore, a researcher has to investigate and ensure if adolescents in their growth stage are consuming enough meat as a part of a balanced diet.

The key strengths of the study are a relatively larger-sized sample cohort and lower recall bias, using actual measurements of weight and height. Despite these strengths, a few limitations of this study should be considered.

First, the subjects of this study were not sampled by a random sampling, and it is difficult to generalize the findings of this study to entire school-aged population. Therefore, future studies should utilize data from a sample survey that can represent a parameter and revalidate the association between meat intake and overweight/obesity.

Second, the survey question included the examples of meat as "beef, pork, chicken, and etc." and of fast food as "hamburgers, pizza, fried food, and etc." It can be inferred that processed meat was included as a part of fast food at responses. However, fish was not mentioned specifically, and it is hard to infer the category for the placement of fish from the responses of different individuals. Therefore, future studies should provide a clearer definition of meat to obtain greater reliability for the measurement of meat intake frequency.

Third, the interpretation of results from the dietary habit survey that puts different types of food that cannot be supplements of each other into a single group is most likely to be ambiguous. In other words, milk and dairy products, depending on their type, have different sugar and fat content, and fruits and vegetables are food groups that cannot be supplements of each other regarding food function and calories. Therefore, these different types of food should be divided into different groups before performing the analysis.

Despite the limitations stated above, the author believe the data from this study assessing the association between meat intake and overweight/obesity in school-aged children will serve as fundamental data for establishing school lunch policies or school health promotion/education. Furthermore, this author has also provided partial evidence to support the need for a change in the social belief of the relationship between meat consumption and obesity.

\section{CONFLICTS OF INTEREST}

The author declares no conflict of interest.

\section{ACKNOWLEDGMENTS}

I sincerely appreciate the kind assistance of the former medical provincial fourth grade official, Hee Woo Lee, M.D., Ph.D., who allowed me to use the data of the Seoul School Health Promotion Center, which made this study possible. 


\section{REFERENCES}

1. Yang M, Xue H, Duan R, Liu Y, Cheng G. Cross-sectional association between food rich in protein and pubertal development among children and adolescents in Chengdu City. Wei Sheng Yan Jiu 2015;44:43-8.

2. Coulson NS, Eiser C, Eiser JR. Nutrition education in the national curriculum. Health Educ J 1998;57:81-8.

3. Naeeni MM, Jafari S, Fouladgar M, Heidari K, Farajzadegan Z, Fakhri M, et al. Nutritional knowledge, practice, and dietary habits among school children and adolescents. Int J Prev Med 2014;5(Suppl 2):171-8.

4. Bes-Rastrollo M, Sánchez-Villegas A, Gómez-Gracia E, Martínez JA, Pajares RM, Martínez-González MA. Predictors of weight gain in a Mediterranean cohort: the Seguimiento Universidad de Navarra Study. Am J Clin Nutr 2006;83:362-70.

5. Rosell M, Appleby P, Spencer E, Key T. Weight gain over 5 years in 21,966 meat-eating, fish-eating, vegetarian, and vegan men and women in EPIC-Oxford. Int J Obes (Lond) 2006; 30:1389-96.

6. Schulz M, Kroke A, Liese AD, Hoffmann K, Bergmann MM, Boeing H. Food groups as predictors for short-term weight changes in men and women of the EPIC-Potsdam cohort. J Nutr 2002;132:1335-40.

7. Paddon-Jones D, Westman E, Mattes RD, Wolfe RR, Astrup A, Westerterp-Plantenga M. Protein, weight management, and satiety. Am J Clin Nutr 2008;87:1558S-61S.

8. Due A, Toubro S, Skov AR, Astrup A. Effect of normal-fat diets, either medium or high in protein, on body weight in overweight subjects: a randomised 1-year trial. Int J Obes Relat Metab Disord 2004;28:1283-90.

9. Foster GD, Wyatt HR, Hill JO, McGuckin BG, Brill C, Mohammed BS, et al. A randomized trial of a low-carbohydrate diet for obesity. N Engl J Med 2003;348:2082-90.

10. Lasker DA, Evans EM, Layman DK. Moderate carbohydrate, moderate protein weight loss diet reduces cardiovascular disease risk compared to high carbohydrate, low protein diet in obese adults: a randomized clinical trial. Nutr Metab (Lond) 2008;5:30.

11.Layman DK, Evans EM, Erickson D, Seyler J, Weber J, Bag- shaw D, et al. A moderate-protein diet produces sustained weight loss and long-term changes in body composition and blood lipids in obese adults. J Nutr 2009;139:514-21.

12. Treyzon L, Chen S, Hong K, Yan E, Carpenter CL, Thames G, et al. A controlled trial of protein enrichment of meal replacements for weight reduction with retention of lean body mass. Nutr J 2008;7:23.

13. Weigle DS, Breen PA, Matthys CC, Callahan HS, Meeuws KE, Burden VR, et al. A high-protein diet induces sustained reductions in appetite, ad libitum caloric intake, and body weight despite compensatory changes in diurnal plasma leptin and ghrelin concentrations. Am J Clin Nutr 2005;82:41-8.

14. Ministry of Education. Manual of school health examination standard survey, 2009-2011. Seoul: Ministry of Education; 2009. p. 20-2.

15. Fung TT, Schulze M, Manson JE, Willett WC, Hu FB. Dietary patterns, meat intake, and the risk of type 2 diabetes in women. Arch Intern Med 2004;164:2235-40.

16. Quatromoni PA, Copenhafer DL, D’Agostino RB, Millen BE. Dietary patterns predict the development of overweight in women: The Framingham Nutrition Studies. J Am Diet Assoc 2002;102:1239-46.

17. Schulze MB, Fung TT, Manson JE, Willett WC, Hu FB. Dietary patterns and changes in body weight in women. Obesity (Silver Spring) 2006;14:1444-53.

18. Héroux M, Janssen I, Lam M, Lee DC, Hebert JR, Sui X, et al. Dietary patterns and the risk of mortality: impact of cardiorespiratory fitness. Int J Epidemiol 2010;39:197-209.

19. Kesse-Guyot E, Bertrais S, Péneau S, Estaquio C, Dauchet L, Vergnaud AC, et al. Dietary patterns and their sociodemographic and behavioural correlates in French middle-aged adults from the SU.VI.MAX cohort. Eur J Clin Nutr 2009;63:521-8.

20. Story M, Neumark-Sztainer D, French S. Individual and environmental influences on adolescent eating behaviors. J Am Diet Assoc 2002;102(Suppl 3):S40-51.

21. Lien N, Lytle LA, Klepp KI. Stability in consumption of fruit, vegetables, and sugary foods in a cohort from age 14 to age 21 . Prev Med 2001;33:217-26.

22. Lytle LA, Seifert S, Greenstein J, McGovern P. How do children's eating patterns and food choices change over time? re- 
sults from a cohort study. Am J Health Promot 2000;14:222-8.

23. Arechavala T, Continente X, Pérez-Giménez A, Bartoll X, Sànchez-Martínez F, López MJ. Food consumption frequency and excess body weight in adolescents in the context of financial crisis in Barcelona (Spain). Gac Sanit 2016;30:457-63.

24. Halkjaer J, Sørensen TI, Tjønneland A, Togo P, Holst C, Heitmann BL. Food and drinking patterns as predictors of 6-year BMI-adjusted changes in waist circumference. Br J Nutr 2004; 92:735-48.

25. Parker DR, Gonzalez S, Derby CA, Gans KM, Lasater TM, Carleton RA. Dietary factors in relation to weight change among men and women from two southeastern New England communities. Int J Obes Relat Metab Disord 1997;21:103-9.

26. Vergnaud AC, Norat T, Romaguera D, Mouw T, May AM, Travier N, et al. Meat consumption and prospective weight change in participants of the EPIC-PANACEA study. Am J Clin Nutr 2010;92:398-407.

27. Buijsse B, Feskens EJ, Schulze MB, Forouhi NG, Wareham NJ, Sharp S, et al. Fruit and vegetable intakes and subsequent changes in body weight in European populations: results from the project on Diet, Obesity, and Genes (DiOGenes). Am J Clin Nutr 2009;90:202-9.

28. Mirmiran P, Esmaillzadeh A, Azizi F. Dairy consumption and body mass index: an inverse relationship. Int J Obes (Lond) 2005;29:115-21.

29. Liu S, Willett WC, Manson JE, Hu FB, Rosner B, Colditz G. Relation between changes in intakes of dietary fiber and grain products and changes in weight and development of obesity among middle-aged women. Am J Clin Nutr 2003;78:920-7.

30. Dror DK, Allen LH. Dairy product intake in children and adolescents in developed countries: trends, nutritional contribution, and a review of association with health outcomes. Nutr Rev 2014;72:68-81.

31. Moreno LA, Bel-Serrat S, Santaliestra-Pasías A, Bueno G. Dairy products, yogurt consumption, and cardiometabolic risk in children and adolescents. Nutr Rev 2015;73 Suppl 1:8-14.

32. ESPGHAN Committee on Nutrition, Agostoni C, Braegger C, Decsi T, Kolacek S, Koletzko B, et al. Role of dietary factors and food habits in the development of childhood obesity: a commentary by the ESPGHAN Committee on Nutrition. J Pediatr Gastroenterol Nutr 2011;52:662-9.

33.Zaborskis A, Lagunaite R, Busha R, Lubiene J. Trend in eating habits among Lithuanian school-aged children in context of social inequality: three cross-sectional surveys 2002, 2006 and 2010. BMC Public Health 2012;12:52. 